\title{
Dopamina, Óxido Nítrico e suas Interações em Modelos para o Estudo da Esquizofrenia
}

\author{
Dopamine, Nitric Oxide and their Interactions in Models \\ for the Study of Schizophrenia
}

\author{
Cristiane Salum*, Ana Carolina de Castro Issy Pereira** \\ \& Elaine Aparecida Del Bel Belluz Guimarães ${ }^{* * *}$ \\ Universidade de São Paulo
}

\begin{abstract}
Resumo
Modelos experimentais baseados no aumento da neurotransmissão dopaminérgica mimetizam aspectos comportamentais e neuroquímicos característicos da esquizofrenia. Psicoestimulantes, como a anfetamina, são utilizados com esta finalidade, pois aumentam os níveis de dopamina extracelular nas vias mesocorticolímbica e mesoestriatal. As limitações da manipulação direta do sistema dopaminérgico incentivam abordagens complementares. O óxido nítrico (NO), um neurotransmissor atípico que inibe a recaptação de dopamina e estimula sua liberação, parece modular comportamentos controlados pelo sistema dopaminérgico. $\mathrm{O}$ teste de inibição pré-pulso revela uma deficiência no filtro sensório-motor, verificada em esquizofrênicos ou após tratamentos com psicotomiméticos, podendo ser prevenida pela inibição do NO. Esta revisão apresenta evidências da interação do NO com o sistema dopaminérgico em modelos para o estudo da esquizofrenia como uma nova ferramenta de investigação desta patologia.

Palavras-chave: Esquizofrenia; dopamina; óxido nítrico; inibição pré-pulso; filtro sensório-motor.
\end{abstract}

\begin{abstract}
Experimental models based on the increase of dopaminergic neurotransmission mimic behavioral and neurochemical schizophrenia-like aspects. Psychostimulants, as amphetamine, are used with this purpose because they increase extracellular dopamine levels in mesocorticolimbic and mesostriatal pathways. The limitations of direct manipulation uniquely based on the dopamine system have encouraged the use of new approaches. Nitric oxide (NO), an atypical neurotransmitter which inhibits dopamine reuptake and stimulates its release, seems to modulate dopamine-controlled behaviors. The prepulse inhibition test reveals deficits on the sensorimotor filter found in schizophrenics or after psichotomimetic treatments. This review presents evidences for the interaction between NO and DA systems on schizophrenia models as a new tool for the investigation of this pathology.

Keywords: Schizophrenia; dopamine; nitric oxide; prepulse inhibition; sensorimotor filter.
\end{abstract}

Por várias décadas a hipótese dopaminérgica da esquizofrenia vem conduzindo as principais investigações sobre sua fisiopatologia. Importantes avanços na compreensão desse distúrbio foram observados durante os últimos 25 anos e esse esforço tem resultado em terapias farmacológicas que reduzem vários de seus sintomas. No entanto, a ampla compreensão dessa desordem cerebral continua distante.
Os modelos baseados na manipulação direta do sistema dopaminérgico apresentam hoje um esgotamento de seu potencial heurístico para investigação da fisiopatologia da esquizofrenia. Alguns modelos experimentais baseados no sistema dopaminérgico são inspirados na farmacologia dos antipsicóticos e envolvem a mensuração de comportamentos; outros reproduzem características pertinentes à esquizofrenia, como o déficit no processamento de informações induzido por apomorfina, ou outros agonistas dopaminérgicos, avaliado por meio do teste da inibição pré-pulso (IPP). Estratégias experimentais complementares às atuais podem possibilitar o desenvolvimento de novos agentes terapêuticos.

O óxido nítrico (NO) é um gás venenoso, instável, considerado recentemente um neurotransmissor atípico. Alterações na distribuição de NO e na presença de seus metabólitos em esquizofrênicos apontam para o envolvimento deste agente na esquizofrenia. Desta forma, o NO representa uma ferramenta auxiliar para a compreensão da 
fisiopatologia da esquizofrenia.

A presente revisão tem como objetivo apresentar evidências da participação do NO em modelos experimentais utilizados para o estudo da esquizofrenia e sua interação com o sistema dopaminérgico.

\section{Esquizofrenia}

A esquizofrenia é considerada a mais severa das desordens psiquiátricas. Com um risco de manifestação em 0,5$1 \%$ da população e surgimento precoce, suas desabilidades resultam nos sintomas negativos e nos déficits cognitivos, enquanto as alucinações e delírios constituem os sintomas positivos ou psicóticos da desordem. Os prejuízos cognitivos na esquizofrenia afetam funções como a atenção, memória e funcionamento intelectual geral (Wong \& Van Tol, 2003).

Enquanto alguns distúrbios, como os das funções motora e cognitiva, podem ser percebidos precocemente, os sintomas clínicos da esquizofrenia aparecem tipicamente entre os 15 e 25 anos de idade no homem e geralmente iniciamse 5 anos mais tarde na mulher. Essa diferença entre os sexos, no período de manifestação da doença, é acompanhada nos homens de uma maior severidade de seu curso, além de anormalidades cerebrais mais pronunciadas e uma maior refratariedade ao tratamento.

Tem sido postulado que a heterogeneidade de sintomas observada nos pacientes esquizofrênicos pode ser decorrente de etiologia ampla. Esta gama de sintomas resultaria de diferentes mecanismos fisiopatológicos ou de diferenças constitucionais inatas atuando em conjunto com fatores ambientais (Duncan, Sheitman \& Lieberman, 1999).

A maioria dos estudos com cérebros de esquizofrênicos post-mortem revela uma diminuição no peso cerebral e um aumento no volume dos ventrículos (Van Horn \& McManus, 1992), além de anormalidades da matéria branca, volume hipocampal reduzido e localização irregular de células corticais (para revisão ver Wong \& Van Tol, 2003). As alterações estruturais macroscópicas encontradas em cérebros de esquizofrênicos podem refletir a vulnerabilidade congênita subjacente a esta doença. A magnitude destas alterações está correlacionada com a expressão clínica dos sintomas da esquizofrenia (Wong \& Van Tol). Estudos de neuroimagem não revelam em pacientes esquizofrênicos a existência de lesões cerebrais localizadas, porém indicam anormalidades em regiões frontais, límbicas e temporais (Wright et al., 2000). Esses achados apontam para a conclusão de que a esquizofrenia é uma doença de múltiplas regiões cerebrais.

Embora o processo fisiopatológico subjacente aos distúrbios neuropsiquiátricos da esquizofrenia seja pouco compreendido, o curso clínico desta doença e uma série de investigações através da pesquisa básica provêem direções para a formulação de modelos fisiopatológicos que podem ser testados empiricamente. Diversos modelos experimentais são utilizados tanto em humanos como em animais para se investigar as bases neuroquímicas e neurofisiológicas de sintomas desta desordem, assim como dos efeitos colaterais dos antipsicóticos.
A hiperfunção do sistema ascendente dopaminérgico é a teoria mais amplamente aceita para se explicar o mecanismo patológico da esquizofrenia. Esta hipótese é baseada em duas principais observações: o antagonismo de receptores do tipo $\mathrm{D}_{2}$ é um pré-requisito essencial para a eficácia terapêutica dos antipsicóticos (neurolépticos) e surtos psicóticos podem ser induzidos em indivíduos sadios por drogas que facilitam ou aumentam a neurotransmissão dopaminérgica (Seeman \& Kapur, 2000). Adicionalmente, a administração aguda de agonistas dopaminérgicos pode precipitar surtos psicóticos em pacientes esquizofrênicos (Moore, West \& Grace, 1999).

Evidências recentes obtidas com tomografia por emissão de pósitron (PET) confirmam que uma hiperatividade da neurotransmissão dopaminérgica está presente em esquizofrênicos. A liberação de DA induzida por anfetamina, a atividade de DOPA descarboxilase e a densidade de receptores $\mathrm{D}_{2}$ no estriado de esquizofrênicos parecem estar elevadas em comparação aos de voluntários sadios, dados estes que se confirmam em pacientes livres de tratamentos com neurolépticos (Abi-Dargham et al., 1998). Além das alterações dopaminérgicas, o GLU também apresenta um papel importante na esquizofrenia. Evidências indicam uma redução da expressão de receptores de GLU (não N-metil-D-aspartato, NMDA) no hipocampo e um aumento da expressão de algumas subunidades dos receptores NMDA no córtex (Eastwood, Kerwin \& Harrison, 1997).

Dentre os candidatos propostos como agentes neuroquímicos relacionados à esquizofrenia, tem sido considerado o envolvimento do NO. Este gás é uma molécula sinalizadora envolvida em muitos eventos celulares que ocorrem nos sistemas nervoso, cardiovascular e imune (Snyder \& Bredt, 1991).

\section{Óxido Nítrico e a Esquizofrenia}

O radical livre NO foi identificado como um mensageiro neuronial com diferentes funções tanto no sistema nervoso central como no periférico. O NO pode atuar como um hormônio, um neurotransmissor, um mensageiro parácrino, um mediador ou ainda como uma molécula citoprotetora e/ou citotóxica (Bernstein, Bogerts \& Keilhoff, 2005). Diferente dos neurotransmissores clássicos, o NO é sintetizado de acordo com a demanda e sensível a um processo de rápida regulação, não sendo armazenado em vesículas, nem tão pouco liberado por exocitose. Por ser um gás lábil, difunde-se por membranas de células pré e pós-sinápticas (Snyder \& Ferris, 2000), formando ligações covalentes com alvos múltiplos, sendo a enzima guanilato ciclase o melhor caracterizado. As enzimas responsáveis pela síntese desse gás são denominadas sintases do óxido nítrico (NOS), constituindo um grupo de enzimas extraordinariamente reguladas que podem ser encontradas em três isoformas: duas delas constitutivas, a neuronal e a endotelial, e uma induzida. Todas as isoformas da enzima NOS sintetizam NO e L-citrulina a partir da L-arginina e do oxigênio molecular em uma reação dependente de diferentes cofatores, entre eles a nicotinamida adenina dinucleotídeo 
(NADPH) (Zhang \& Snyder, 1995). Foi demonstrado que em tecidos fixados a atividade da NOS corresponde à atividade histoquímica da NADPH-diaforase (NADPH-d).

A enzima NOS está fisicamente ligada ao receptor NMDA através da proteína PSD-95 (Esplugues, 2002). Sendo assim, no cérebro, o NO é produzido pela NOS neuronal quase que exclusivamente pela ativação dos receptores glutamatérgicos do tipo NMDA. Apesar dos neurônios que contêm NOS representarem apenas $1 \%$ das células neuroniais, a ramificação de seus axônios é tão extensa que parece atingir a grande maioria das células cerebrais.

Há evidências de que a formação excessiva de NO possa ser neurotóxica. Uma série de estudos tem demonstrado que a estimulação da produção de NO, através dos substratos de NOS, $\mathrm{N}^{\mathrm{G}}$-hidroxi-L-arginina (H-ARG) ou L-arginina, produz um aumento da liberação de DA e de GLU no estriado e em outras regiões cerebrais. Por sua vez, a inibi- ção de NOS por meio de inibidores enzimáticos como o 7nitroindazole (7-NI) produz efeito oposto (Kiss \& Vizi, 2001). Desta forma, diversos trabalhos têm mostrado que o NO exerce funções mediadoras atuando como modulador no controle de atividades comportamentais (para revisão ver (Snyder \& Ferris, 2000). Trabalhos in vitro e in vivo sugerem que o NO endógeno desempenha um efeito inibitório sobre os transportadores de monoaminas. Assim, o NO parece agir inibindo a recaptação de DA e aumentando a liberação deste neurotransmissor (Kiss \& Vizi, 2001; Rocchitta et al., 2005) (Figura 1). Esta atuação do NO pode representar uma nova forma de comunicação interneuronal, ou seja, uma interação não-sináptica independente de receptores. Tendo em vista a interação entre os sistemas dopaminérgico, glutamatérgico e nitrérgico (West, Galloway \& Grace, 2002), evidências de um provável envolvimento do NO e a esquizofrenia têm sido obtidas.

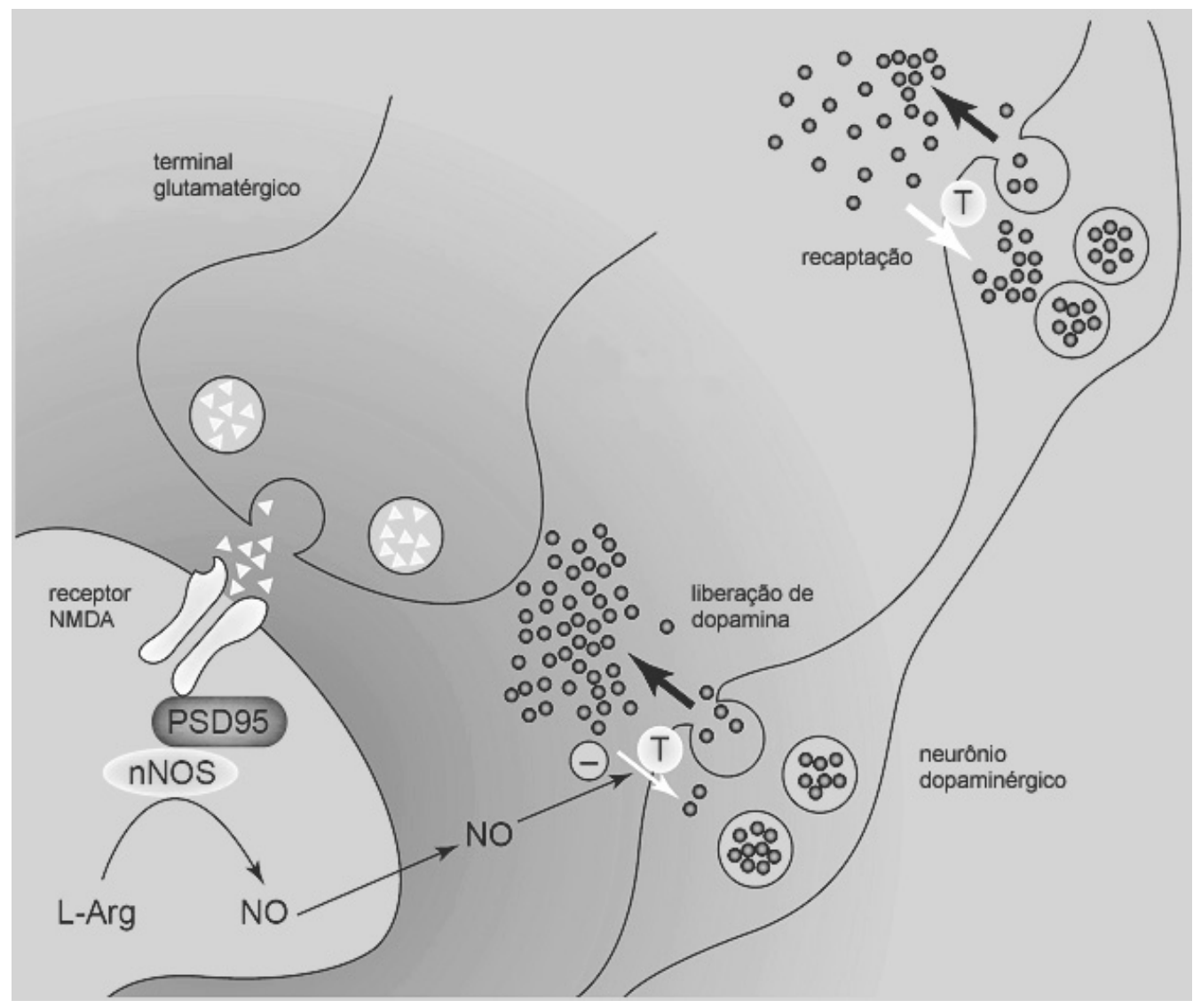

Figura 1. Ilustração da liberação do NO a partir da ativação dos receptores glutamatérgicos do tipo NMDA e sua interferência na terminação dopaminérgica. A liberação do glutamato ativa os receptores glutamatérgicos NMDA pós-sinápticos e promove influxo de $\mathrm{Ca}^{+}$, que ativa a enzima NOS e estimula a formação do NO, a partir do aminoácido L-arginina. O NO liberado inibe a atividade do transportador de dopamina, diminuindo a sua recaptação e aumentando sua liberação nas terminações dopaminérgicas próximas às sinapses glutamatérgicas. Modificado de Kiss e Vizi (2001).

Alterações no sistema nitrérgico de esquizofrênicos são evidenciadas pela observação de uma baixa densidade de neurônios NADPH-d positivos nos córtices frontal e temporal e o aumento na densidade destas células na substância branca das regiões frontais e temporais (Akbarian et al., 1993). Esta distribuição alterada tem sido relacionada à diminuição nos níveis estáveis de metabólitos de NO, nitrito e nitrato, nos fluidos cérebro-espinhais destes pacientes (Ramirez, Garnica, Boll, Montes \& Rios, 2004). Por outro lado, a produção excessiva de NO no cérebro de 
esquizofrênicos foi observada em regiões que podem prover entrada excitatória crítica ao sistema dopaminérgico mesencefálico (Garcia-Rill et al., 1995). Adicionalmente, verificou-se no plasma de pacientes esquizofrênicos um aumento de NO (Akyol et al., 2002)

Manipulações que afetam o sistema nitrérgico também têm demonstrado provocar alterações comportamentais e histoquímicas em modelos animais para o estudo da esquizofrenia.

\section{Modelos Animais para o Estudo da Esquizofrenia}

A investigação científica de doenças psiquiátricas e neurológicas necessita do desenvolvimento adequado, ainda que limitado, de modelos animais. A utilização desses modelos para o estudo da esquizofrenia é um grande desafio, dada a complexidade desta doença. Esses modelos não são capazes de reproduzir características fisiopatológicas das doenças mentais em sua totalidade, uma vez que não podem retratar fielmente sintomas cognitivos, emocionais e de percepção das doenças humanas (Lipska \& Weinberger, 2000; Marcotte, Pearson \& Srivastava, 2001).

$\mathrm{Na}$ esquizofrenia, grande parte dos modelos não preenche todos os critérios de validade propostos, sendo eles: (a) validade de correlação ou preditiva - correlação entre os efeitos da droga na situação clínica e no modelo; (b) analogia - semelhança entre o comportamento do animal no teste e a apresentação clínica do distúrbio e (c) homologia - semelhança entre a neurobiologia subjacente ao distúrbio e o comportamento observado no modelo. Tradicionalmente, os modelos animais envolvem fenômenos ligados à DA ou ainda à manipulação do sistema glutamatérgico. Essas manipulações destinam-se à reprodução experimental de características comportamentais e/ou cognitivas semelhantes às observadas na esquizofrenia.

As manifestações induzidas por agonistas dopaminérgicos, como a anfetamina e apomorfina, incluem a hiperatividade motora, a estereotipia (Lipska \& Weinberger, 2000), além de déficits de atenção seletiva ou no filtro sensóriomotor, que podem ser avaliados através dos modelos de inibição latente ou bloqueio de Kamin (Gray et al., 1997; O'Tuathaigh et al., 2003) e inibição pré-pulso (Weiss \& Feldon, 2001), respectivamente. Por outro lado, os efeitos de drogas que antagonizam receptores dopaminérgicos, tais como as utilizadas para o tratamento da esquizofrenia, podem ser estudados por meio do teste de catalepsia, caracterizada pela manutenção de posturas incorretas ou pouco usuais dos animais. Este modelo responde unicamente ao critério de validade preditiva e não está relacionado à ação terapêutica dos antipsicóticos, mas a um de seus efeitos colaterais (Marras, Martins, Del Bel \& Guimaraes, 1995).

Adicionalmente, o bloqueio farmacológico dos receptores glutamatérgicos em roedores pela fenciclidina e seus análogos promove efeitos comportamentais compatíveis à sintomatologia da esquizofrenia, similares àqueles induzidos por agonistas dopaminérgicos (Klamer, Engel \& Svensson, 2004b; Klamer, Zhang, Engel \& Svensson, 2005). Portanto, os modelos animais de esquizofrenia podem ser considerados manipulações experimentais que promovem modi- ficações comportamentais ou neuroquímicas semelhantes às observadas nessa patologia (Marcotte et al., 2001).

A heterogeneidade da esquizofrenia propicia que sua causa e progressão sejam investigadas com base em diferentes teorias que incluem a possibilidade de um desenvolvimento neural anormal, susceptibilidade genética e a ocorrência de distúrbio neuroquímico (Duncan et al., 1999).

A teoria de que a esquizofrenia seria uma doença relacionada ao desenvolvimento neural permitiu a elaboração de modelos animais baseados na lesão do sistema nervoso central, por meio de diferentes agentes excitotóxicos ou de intervenções distintas no período neonatal (Marcotte et al., 2001). As manipulações experimentais neonatais incluem o tratamento crônico com antagonista glutamatérgico do tipo NMDA (Harris, Sharp, Gartlon, Jones \& Harrison, 2003) ou com inibidores da enzima de síntese do NO promovendo uma interferência precoce no sistema nitrérgico (Black, Simmonds, Senyah \& Wettstein, 2002). Como conseqüência, podem ser observadas modificações nas respostas induzidas pela anfetamina e pela fenciclidina. A lesão neonatal do hipocampo tem demonstrado promover em ratos, jovens e adultos, intensas alterações comportamentais relacionadas ao aumento da neurotransmissão dopaminérgica mesolímbica e nigroestriatal. São exemplos, a hiperresponsividade motora aos estimulantes e ao estresse, o aumento de estereotipias, a sensibilidade aos antagonistas glutamatérgicos e a deficiência na resposta de inibição pré-pulso ao reflexo de sobressalto (Lipska, 2004).

A manipulação dos sistemas dopaminérgico e glutamatérgico, em conjunto com a utilização de inibidores e/ou doadores de óxido nítrico, permite o estudo do envolvimento desse agente na esquizofrenia. Alguns estudos apontam para a possibilidade de que os efeitos comportamentais produzidos por antagonistas de receptores glutamatérgicos do tipo NMDA, tais como a fenciclidina, a ketamina e o MK801, possam ser mediados pelo sistema NO. Além disso, a disponibilidade crescente de linhagens transgênicas de camundongos (animais knockout) oferece oportunidade para o estudo do impacto de mutações genéticas no sistema nitrérgico sobre os sintomas e mecanismos da doença.

Bird, Bujas-Bobanovic, Robertson e Dursun (2001) demonstraram que quando a expressão da NOS neuronial é diminuída (animais tratados com oligonucleotídeo antisense - knockdown), ou abolida (animais knockout), os efeitos induzidos pela fenciclidina não podem ser obtidos plenamente, indicando a necessidade de integridade do sistema NO para manifestação plena destes efeitos.

Adicionalmente, Deustch et al. (1996) observaram que a aplicação sistêmica do inibidor da NOS, 7-NI, atenuou o comportamento de saltos explosivos episódicos ou popping em camundongos, eliciado pela aplicação de MK801. Os autores sugerem que o comportamento de "popping" seja um modelo para o estudo da esquizofrenia desde que é inibido/ antagonizado por antipsicóticos típicos e atípicos.

Em contraste, Noda, Yamada, Furukawa e Nabeshima (1995) evidenciaram que a aplicação de fenciclidina em camundongos, que induz hiperlocomoção, comportamen- 
tos estereotipados, ataxia e sniffing, além de deficiência na coordenação motora, não podem ser revertidos pelos inibidores da NOS, $\mathrm{N}^{\mathrm{G}}$-nitro-L-arginina metil ester (LNAME) e 7-NI.

No que se refere ao sistema dopaminérgico, tem sido observada uma interação in vivo e in vitro com o sistema nitrérgico (Hu, Lee \& el Fakahany, 1994). Os inibidores da NOS são capazes de mimetizar as ações de drogas antipsicóticas em roedores, induzindo a catalepsia (Marras et al., 1995) e reduzindo sua atividade locomotora e exploratória (Del Bel, Souza, Guimaraes, da Silva \& Nucci-daSilva, 2002). Em camundongos, a catalepsia induzida pelo inibidor não-seletivo da NOS, N ${ }^{\text {̀̀ }}$-nitro-L-arginina (L-NOARG) exibe tolerância cruzada ao haloperidol depois de um tratamento subcrônico e pode ser potencializada por sua administração prévia (Del Bel \& Guimaraes, 2000). Este efeito poderia ser resultante da interferência do sistema nitrérgico na coordenação dos movimentos. É sugerido que os mecanismos subjacentes aos efeitos motores dos inibidores da NOS envolvam a neurotransmissão dopaminérgica na via mesolímbica ou mesocortical (Morris et al., 1997).

Estas interações entre os sistemas dopaminérgico e/ou glutamatérgico com o sistema do NO também podem ser verificadas no modelo de filtro sensório-motor, o teste de inibição pré-pulso. O fato da inibição pré-pulso ser um modelo comportamental com alto valor preditivo, ou seja, a administração de psicoestimulantes a voluntários sadios provoca um déficit na inibição pré-pulso semelhante ao obtido em roedores (Swerdlow et al., 2003), faz deste modelo uma ferramenta eficaz tanto para investigar os sintomas cognitivos da doença, como para a descoberta de novos fármacos.

\section{Inibição Pré-pulso e a Esquizofrenia}

O teste de inibição pré-pulso (IPP) oferece uma medida operacional do filtro sensório-motor refletido pela capacidade de inibição de um reflexo de sobressalto, quando um estímulo sensorial é precedido por outro de menor intensi-

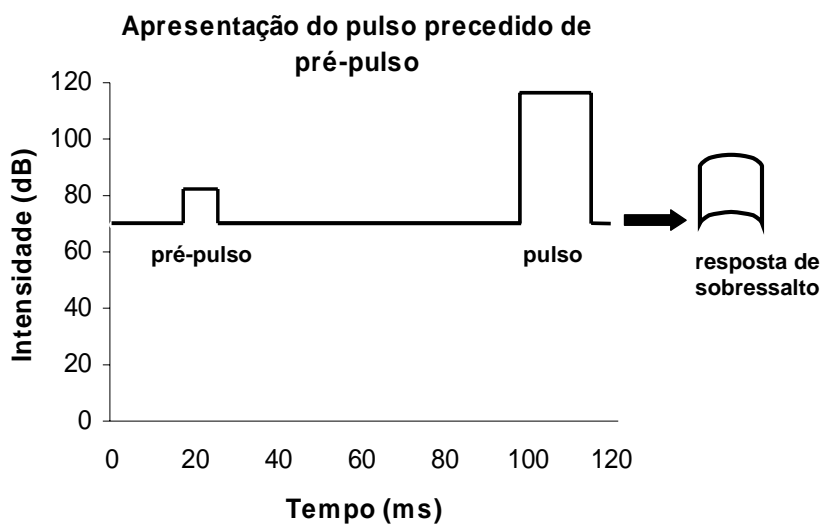

dade (Hoffman \& Ison, 1980). Esse reflexo pode ser observado em diferentes espécies de mamíferos, incluindo humanos, primatas e roedores (Weiss \& Feldon, 2001).

O filtro sensório-motor provê ao indivíduo a capacidade de discriminar estímulos externos de relevância fisiológica ou cognitiva, habilidade essa que está comprometida nos portadores de algumas desordens psiquiátricas. Portanto, esse é um modelo que explora um aspecto peculiar da esquizofrenia, o déficit no processamento de informações (Braff \& Geyer, 1990). A IPP é um modelo utilizado para o estudo do controle neural exercido por estruturas corticais e límbicas sobre processos de filtro e sua possível deficiência em desordens neuropsiquiátricas. Esse processo parece atuar como um filtro de estímulos sensoriais protegendo o sistema nervoso contra um excesso de informações (Weiss \& Feldon, 2001).

O reflexo de sobressalto é uma resposta natural de defesa que envolve uma rápida contração dos músculos da face e do corpo e ocorre em resposta a um estímulo intenso e inesperado (Weiss \& Feldon, 2001). Esta reação é uma resposta incontrolável e espontânea que pode ser eliciada por diferentes modalidades de estímulos (auditivo, visual ou tátil) (Hoffman \& Ison, 1980). Devido ao fato do circuito neural responsável envolver poucas sinapses, a latência de resposta de sobressalto é muito pequena, entre 5 e $10 \mathrm{~ms}$ (Fendt, Li \& Yeomans, 2001). A IPP é uma forma de plasticidade do reflexo do sobressalto, caracterizada por uma redução normal no sobressalto em resposta a um estímulo auditivo intenso (pulso), quando este é precedido imediatamente (30-500 ms) por um estímulo mais fraco (prépulso) (Braff et al., 1978) (Figura 2). A ativação de processos cerebrais é aumentada em resposta ao estímulo fraco, impedindo a responsividade a eventos sensoriais subseqüentes durante uma breve janela temporal. Este período protege a informação contida no estímulo inicial, para que seja adequadamente processado, durante o qual, apenas estímulos suficientemente salientes serão capazes de ultrapassar este filtro protetor.

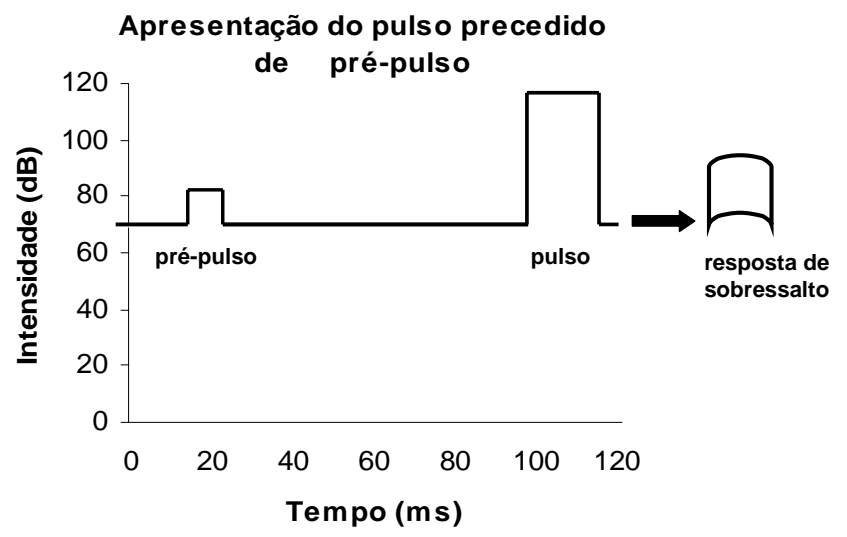

Figura 2. Esquema simplificado do mecanismo de inibição pré-pulso (IPP). A IPP é caracterizada por uma redução na amplitude do sobressalto que ocorre em resposta a um estímulo auditivo intenso (pulso), quando este é precedido imediatamente (30-500 ms) por um estímulo mais fraco (pré-pulso). Reflexo de sobressalto em resposta ao pulso (Figura 2A) e reflexo de sobressalto em resposta ao pulso precedido de pré-pulso (Figura 2B). Modificadas de Braff et al. (1978). 
Geralmente, a IPP é expressa como a porcentagem de inibição da amplitude do sobressalto em resposta a múltiplas apresentações do pulso precedido pelo pré-pulso, em função da amplitude da resposta apenas ao pulso (Hoffman \& Ison, 1980).

Além do circuito neural envolvido no sobressalto, que inclui colículo inferior, colículo superior e o núcleo tegmentar pedúnculo - pontino, a IPP é modulada por estruturas córtico-límbicas tais como núcleo accumbens, hipocampo, amígdala e córtex pré-frontal e parece ser mediada por um circuito bastante coincidente com o mesolímbico dopaminérgico (para revisão ver Swerdlow, Caine, Braff \& Geyer, 1992).

Drogas que induzem sintomas da esquizofrenia em humanos, como a anfetamina, cocaína e a apomorfina reduzem a IPP (Zhang, Forkstam, Engel \& Svensson, 2000); esse efeito pode ser diminuído pelo tratamento com antipsicóticos típicos e atípicos, mas nem sempre é abolido (Kumari, Soni \& Sharma, 2002). A modulação dopaminérgica da IPP é complexa e variável entre as espécies (Swerdlow et al., 2004). O prejuízo na IPP causado por agonistas dopaminérgicos envolve a estimulação de mais de um subtipo de receptor para sua completa manifestação. Cinco subtipos de receptores de DA foram identificados no cérebro e divididos em duas famílias: receptores da família-D ${ }_{1}$ e da família- $D_{2}$ (Missale, Nash, Robinson, Jaber \& Caron, 1998). Baixas doses de SKF82958, um agonista dopaminérgico seletivo para receptores do tipo $\mathrm{D}_{1}$, promovem prejuízo na IPP em camundongos, o que não é observado com agonistas seletivos da família $\mathrm{D}_{2}$, como o quimpirole (Paladini, Robinson, Morikawa, Williams \& Palmiter, 2003). Em contrapartida, o oposto ocorre em ratos, nos quais a estimulação dos receptores do tipo $\mathrm{D}_{2}$ parece ser a mais importante para promover os déficits na IPP (Zhang et al., 2000), embora seja sugerido um possível sinergismo entre estes receptores (Wan, Geyer \& Swerdlow, 1995) na modulação do filtro sensório-motor.

Estudos com microdiálise revelaram que o aumento e posterior diminuição do fluxo de DA no núcleo acumbens, pela administração de anfetamina, é acompanhado por uma correspondente redução e aumento na IPP (Zhang et al.). Assim, a magnitude da IPP parece estar inversamente relacionada com os níveis de DOPAC e de DA no accumbens (Yamada, Harano \& Tanaka, 1998). Humby, Wilkinson, Robbins e Geyer (1996) relataram diferenças significativas nos níveis extracelulares de DA no núcleo accumbens durante a apresentação do pulso sozinho em relação àqueles obtidos durante a apresentação do pulso precedido de pré-pulso. Tem sido sugerido que este efeito sobre os níveis extracelulares dopaminérgicos poderia resultar de uma retroinibição dos neurônios dopaminérgicos causada pela ativação dos auto-receptores, quando um fraco pré-pulso fosse apresentado. Sendo assim, uma baixa IPP poderia estar associada a uma baixa sensibilidade dos auto-receptores que modulam a liberação de DA (Yamada et al.).

Em um estudo visando explorar as contribuições de receptores específicos da família $\mathrm{D}_{2}\left(\mathrm{D}_{2}, \mathrm{D}_{3}\right.$ e $\left.\mathrm{D}_{4}\right)$, não foram observadas diferenças conclusivas nas respostas de IPP entre os agonistas dopaminérgicos, apomorfina, bromocriptina e 7-OHDPAT, com distintas afinidades por estes receptores (Caine, Geyer \& Swerdlow, 1995). Entretanto, apenas o antagonista haloperidol, com alta afinidade por receptores $\mathrm{D}_{2}$, foi capaz de prevenir o déficit na IPP causado por aqueles agonistas, dando suporte à hipótese de que agentes dopaminérgicos modulam a IPP através dos receptores $D_{2}$. Por outro lado, estudos mais recentes têm demonstrado a capacidade de agonistas $\mathrm{D}_{3}$, tais como, 7-OHDPAT e quinerolane, de prejudicarem a IPP (Varty \& Higgins, 1998). Sugere-se que a ativação de receptores $D_{3}$ prejudique a normalização da liberação dopaminérgica no accumbens produzida pelo pré-pulso. Interessantemente, o quinerolane foi capaz de prejudicar a IPP apenas na dose mais elevada (Varty \& Higgins). A ação dual deste agonista parece corresponder à sua falta de seletividade por receptores $\mathrm{D}_{3}$, entretanto, permanece incerto se seu efeito no núcleo accumbens mediado por esses receptores ocorre através dos auto-receptores terminais e/ ou dos receptores póssinápticos.

Apesar desta ampla investigação, a compreensão total dos efeitos de compostos dopaminérgicos na IPP ainda não foi alcançada. A influência do NO nestes efeitos têm contribuído para o esclarecimento da participação da DA neste modelo.

Óxido Nítrico, Dopamina e o Teste de Inibição Pré-pulso

O prejuízo da IPP em ratos causado por alguns antagonistas glutamatérgicos pode ser atenuado por inibidores da enzima de síntese do NO (Johansson, Jackson \& Svensson, 1997); a administração isolada desses inibidores não altera a IPP, porém pode provocar um aumento na resposta de sobressalto acústico ao pulso. Em camundongos, o tratamento com L-NAME, inibidor não-seletivo da NOS neuronial, ou $\mathrm{N}^{\grave{u}}$-propil-L-arginina (L-NPA), um inibidor seletivo da NOS neuronial, diminui o efeito da fenciclidina na IPP de forma dose-dependente (Klamer, Engel \& Svensson, 2001; Klamer et al., 2004b), sendo o mesmo efeito observado com o azul de metileno, um inibidor da guanilato ciclase (Klamer, Engel \& Svensson, 2004a). De acordo com a proposta de West et al. (2002), as aferências glutamatérgicas mantêm os níveis tônicos de DA extracelular de forma direta, ativando receptores ionotrópicos glutamatérgicos localizados em terminais dopaminérgicos, e de forma indireta via interneurônios que contêm NOS no estriado. Portanto, esta interação entre os sistemas glutamatérgico e nitrérgico na mediação da IPP, provavelmente se deva ao controle que estes sistemas exercem sobre a liberação dopaminérgica.

Dados recentes obtidos em nosso laboratório (Salum, Guimaraes, Brandao \& Del Bel, 2006) ilustram a interação entre os sistemas nitrérgico e dopaminérgico na modulação da IPP em ratos Wistar. O pré-tratamento com o LNOARG, $40 \mathrm{mg} / \mathrm{kg}$, foi capaz de prevenir o prejuízo na IPP induzido por anfetamina, mas não aquele causado por apomorfina, sugerindo que a interação entre o L-NOARG e a anfetamina ocorra a nível pré-sináptico. Embora outro 
estudo não tenha encontrado efeito semelhante do LNAME (10 mg/kg) (Johansson et al., 1997) sobre a ação da anfetamina na IPP, diferenças entre as doses, raça do rato e/ ou parâmetros da IPP utilizados nestes estudos podem explicar esta divergência, além das possíveis diferenças na potência destes compostos.

Em contrapartida, L-NOARG não modificou significativamente os efeitos da bromocriptina e do quimpirole na IPP, embora este último tenha apresentado uma interação com o L-NOARG nas respostas de sobressalto acústico ao pulso e ao pré-pulso seguido de pulso. Estes achados fortalecem a hipótese de uma interação a nível pré-sináptico entre os sistemas dopaminérgico e nitrérgico. A anfetamina, um agonista dopaminérgico indireto, atua como um falso neurotransmissor, entrando no citoplasma por meio dos transportadores pré-sinápticos e ocupando o transportador monoaminérgico vesicular (VMAT2) facilitando a liberação de DA além de bloquear sua recaptação (Sulzer, Maidment \& Rayport, 1993). O quimpirole é um agonista da família- $\mathrm{D}_{2}$ que apresenta superior afinidade pelos receptores $\mathrm{D}_{3}$, os quais estão localizados, preferencialmente, em terminais pré-sinápticos e possuem uma ação inibitória sobre a síntese de DA (Millan et al., 2002)

\section{Discussão}

Existem sólidas evidências de que o NO exerce uma influência excitatória primária sobre as neurotransmissões fásica e tônica de DA em condições fisiológicas (West et al., 2002). Mais especificamente, o NO aumenta a liberação de DA e inibe sua recaptação, enquanto que agentes inibidores da síntese de NO promovem efeito oposto (Kiss \& Vizi, 2001; West \& Galloway, 1997). Dessa forma, o NO pode desempenhar um papel importante na integração da informação transmitida aos núcleos da base, mediando e/ou regulando aspectos diversos da neurotransmissão dopaminérgica.

Recentemente, a participação do NO na esquizofrenia tem sido evidenciada por meio de investigações postmortem, exames laboratoriais e, em maior escala, através de avaliações comportamentais em modelos animais. A distribuição alterada de NADPH-d em cérebros de indivíduos esquizofrênicos aponta para a possibilidade de que alterações no sistema nitrérgico estejam envolvidas nesta patologia. Tais alterações na expressão de NOS neuronal podem influenciar os padrões corticais de neurotransmissores e receptores, e assim, interferir em circuitos neuronais alterados na esquizofrenia (Bernstein et al., 2005). Estudos genéticos recentes revelam o polimorfismo do gene da NOS neuronal confere maior susceptibilidade à doença. No entanto, os achados bioquímicos da expressão da NOS neuronal no neocórtex de esquizofrênicos permanecem contraditórios.

Considerável esforço tem sido feito para o desenvolvimento de modelos animais direcionados ao estudo da esquizofrenia, com o objetivo de mimetizar características neurobiológicas e manifestações desta desordem humana.
O fato de inibidores da NOS prejudicarem ou bloquearem comportamentos induzidos por agentes psicóticos, produzindo efeitos semelhantes aos de antipsicóticos típicos (Klamer et al., 2005), justifica o interesse pela investigação do papel do NO sobre comportamentos do tipo esquizofrênico evocados experimentalmente. Entretanto, o mecanismo da interação NO-DA ainda é pouco compreendido.

Os modelos animais da catalepsia e IPP corroboram o envolvimento do NO em disfunções comportamentais decorrentes de hiperfunção dopaminérgica. A inibição da sintase do NO pode potencializar a catalepsia induzida por haloperidol e prevenir o déficit na IPP causado por anfetamina (Del Bel \& Guimaraes, 2000; Salum et al., 2006). Dado que agonistas dopaminérgicos diretos tais como a apomorfina, o SKF38393, bromocriptina e o quimpirole não apresentam interação com o L-NOARG na resposta de inibição pré-pulso, é provável que a influência exercida pelo NO neste processo não envolva ação direta nos receptores dopaminérgicos. A capacidade do L-NOARG de prevenir os prejuízos causados unicamente pela anfetamina na IPP sugere que a interação entre estas drogas ocorra ao nível pré-sináptico.

West et al. (2002) sugerem através de um modelo teórico que uma hiperatividade do sistema nitrérgico pode agir paralelamente à hiperfunção dopaminérgica característica da esquizofrenia.

De acordo com este modelo, uma disfunção em vias córtico-estriatais dependentes de NO poderia prejudicar a operação de circuitos de retropropagação estriado-nigrais envolvidos na regulação da transmissão dopaminérgica. Esta disfunção dopaminérgica poderia alterar o processamento de informações sensório-motoras em projeções neuronais e resultar em uma seleção imprópria ou inativação dos circuitos de saída do estriado envolvidos no controle de áreas pré-motoras do tronco cerebral e tálamo. É sugerido que os papéis moduladores do NO na sinalização das vias de DA e GLU envolvidas na integração das estruturas límbicas são um novo alvo para a farmacoterapia da esquizofrenia.

\section{Conclusão}

Embora os modelos animais para o estudo da esquizofrenia não reproduzam fielmente as características sintomatológicas desta desordem, dada a complexidade e subjetividade da mesma, os dados obtidos até o presente momento sustentam a interação entre os sistemas DA e NO na modulação de determinadas manifestações desta doença. Mais especificamente, esta interação tem sido demonstrada no modelo de déficit no sistema de filtro sensório-motor e na catalepsia. A interação entre os sistemas dopaminérgico e nitrérgico fornece novas perspectivas para a compreensão dos mecanismos fisiopatológicos e neuroquímicos de várias desordens mentais. $\mathrm{O}$ crescente interesse por examinar a dinâmica da interação entre $\mathrm{NO}$ e DA tem o potencial de revelar novas estratégias terapêuticas para essas desordens. 


\section{Referências}

Abi-Dargham, A., Gil, R., Krystal, J., Baldwin, R. M., Seibyl, J. P., Bowers, M., van Dyck, C. H., Charney, D. S., Innis, R. B., \& Laruelle, M. (1998). Increased striatal dopamine transmission in schizophrenia: Confirmation in a second cohort. American Journal of Psychiatry, 155, 761-767.

Akbarian, S., Bunney, W. E., Potkin, S. G., Wigal, S. B., Hagman, J. O., \& Jones, E. G. (1993). Altered distribution of nicotinamide-adenine dinucleotide phosphate-diaphorase cells in frontal lobe of schizophrenics implies disturbance of cortical development. Archives of General Psychiatry, 50, 169-177.

Akyol, O., Herken, H., Uz, E., Fadillioglu, E., Unal, S., Sogut, S., Ozyurt, H., \& Savas, H. A. (2002). The indices of endogenous oxidative and antioxidative processes in plasma from schizophrenic patients. The possible role of oxidant/ antioxidant imbalance. Progress in Neuropsychopharmacology \& Biological Psychiatry, 26, 995-1005.

Bernstein, H. G., Bogerts, B., \& Keilhoff, G. (2005). The many faces of nitric oxide in schizophrenia. A review. Schizophrenia Research, 78, 69-86.

Bird, D. C., Bujas-Bobanovic, M., Robertson, H. A., \& Dursun, S. M. (2001). Lack of phencyclidine-induced effects in mice with reduced neuronal nitric oxide synthase. Psychopharmacology (Berl), 155, 299-309.

Black, M. D., Simmonds, J., Senyah, Y., \& Wettstein, J. G. (2002). Neonatal nitric oxide synthase inhibition: Social interaction deficits in adulthood and reversal by antipsychotic drugs. Neuropharmacology, 42, 414-420.

Braff, D. L., \& Geyer, M. A. (1990). Sensorimotor gating and schizophrenia. Human and animal model studies. Archives of General Psychiatry, 47, 181-188.

Braff, D. L., Stone, C., Callaway, E., Geyer, M. A., Glick, I., \& Bali, L. (1978). Prestimulus effects on human startle reflex in normals and schizophrenics. Psychophysiology, 15, 339-343.

Caine, S. B., Geyer, M. A., \& Swerdlow, N. R. (1995). Effects of D3/D2 dopamine receptor agonists and antagonists on prepulse inhibition of acoustic startle in the rat. Neuropsychopharmachology, 12, 141-145.

Del Bel, E. A., \& Guimaraes, F. S. (2000). Sub-chronic inhibition of nitric-oxide synthesis modifies haloperidol-induced catalepsy and the number of NADPH-diaphorase neurons in mice. Psychopharmacology (Berl), 147, 356-361.

Del Bel, E. A., Souza, A. S., Guimaraes, F. S., da Silva, C. A., \& Nucci-da-Silva, L. P. (2002). Motor effects of acute and chronic inhibition of nitric oxide synthesis in mice. Psychopharmacology (Berl), 161, 32-37.

Deustch, S. I., Rosse, R. B., Paul, S. M., Tomasino, V., Koetzner, L., Morn, C. B., \& Mastropaolo, J. (1996). 7-Nitroindazole and methylene blue, inhibitors of neuronal nitric oxide synthase and NO-stimulated guanylate cyclase, block MK-801-elicited behaviors in mice. Neuropsychopharmacology, 15, 37-43.

Duncan, G. E., Sheitman, B. B., \& Lieberman, J. A. (1999). An integrated view of pathophysiological models of schizophrenia. Brain Research, 29, 250-264.

Eastwood, S. L., Kerwin, R. W., \& Harrison, P. J. (1997). Immunoautoradiographic evidence for a loss of alpha-amino3-hydroxy-5-methyl-4-isoxazole propionate-preferring non-Nmethyl-D-aspartate glutamate receptors within the medial temporal lobe in schizophrenia. Biological Psychiatry, 41, 636643.

Esplugues, J. (2002). NO as signalling molecule in the nervous system. British Journal of Pharmacology, 135, 1079-1095.
Fendt, M., Li, L., \& Yeomans, J. S. (2001). Brain stem circuits mediating prepulse inhibition of the startle reflex. Psychopharmacology, 156, 216-224.

Garcia-Rill, E., Biedermann, J. A., Chambers, T., Skinner, R. D., Mrak, R. E., Husain, M., \& Karson, C. N. (1995). Mesopontine neurons in schizophrenia. Neuroscience, 66, 321335.

Gray, J. A., Moran, P. M., Grigoryan, G., Peters, S. L., Young, A. M., \& Joseph, M. H. (1997). Latent inhibition: The nucleus accumbens connection revisited. Behavioural Brain Research, $88,27-34$.

Harris, L. W., Sharp, T., Gartlon, J., Jones, D. N., \& Harrison, P. J. (2003). Long-term behavioural, molecular and morphological effects of neonatal NMDA receptor antagonism. The European Journal of Neuroscience, 18, 1706-1710.

Hoffman, H. S., \& Ison, J. R. (1980). Reflex modulation in the domain of startle: I Some empirical findings and their implications for how the nervous system processes sensory input. Psychological Review, 87, 175-189.

$\mathrm{Hu}$, J., Lee, J. H., \& el Fakahany, E. E. (1994). Inhibition of neuronal nitric oxide synthase by antipsychotic drugs. Psychopharmacology (Berl), 114, 161-166.

Humby, T., Wilkinson, L. S., Robbins, T. W., \& Geyer, M. A. (1996). Prepulses inhibit startle-induced reductions of extracellular dopamine in the nucleus accumbens of rat. Journal of Neuroscience, 16, 2149-2156.

Johansson, C., Jackson, D. M., \& Svensson, L. (1997). Nitric oxide synthase inhibition blocks phencyclidine-induced behavioural effects on prepulse inhibition and locomotor activity in the rat. Psychopharmacology, 131, 167-173.

Kiss, J. P., \& Vizi, E. S. (2001). Nitric oxide: A novel link between synaptic and nonsynaptic transmission. Trends in Neurosciences, 24, 211-215.

Klamer, D., Engel, J. A., \& Svensson, L. (2001). The nitric oxide synthase inhibitor, L-NAME, block phencyclidine-induced disruption of prepulse inhibition in mice. Psychopharmacology (Berl), 156, 182-186.

Klamer, D., Engel, J. A., \& Svensson, L. (2004a). Phencyclidineinduced behaviour in mice prevented by methylene blue. Basic \& Clinical Pharmacology \& Toxicology, 94, 65-72.

Klamer, D., Engel, J. A., \& Svensson, L. (2004b). The neuronal selective nitric oxide synthase inhibitor, Nomega-propyl-Larginine, blocks the effects of phencyclidine on prepulse inhibition and locomotor activity in mice. European Journal of Pharmacology, 503, 103-107.

Klamer, D., Zhang, J., Engel, J. A., \& Svensson, L. (2005). Selective interaction of nitric oxide synthase inhibition with phencyclidine: Behavioural and NMDA receptor binding studies in the rat. Behavioural Brain Research, 159, 95-103.

Kumari, V., Soni, W., \& Sharma, T. (2002). Prepulse inhibition of the startle response in risperidone-treated patients: Comparison with typical antipsychotics. Schizophrenia Research, 55, 139-146.

Lipska, B. K. (2004). Using animal models to test a neurodevelopmental hypothesis of schizophrenia. Journal of Psychiatry \& Neuroscience, 29, 282-286.

Lipska, B. K., \& Weinberger, D. R. (2000). To model a psychiatric disorder in animals: Schizophrenia as a reality test. Neuropsychopharmacology, 23, 223-239.

Marcotte, E. R., Pearson, D. M., \& Srivastava, L. K. (2001). Animal models of schizophrenia: A critical review. Journal of Psychiatry \& Neuroscience, 26, 395-410.

Marras, R. A., Martins, A. P., Del Bel, E. A., \& Guimaraes, F. S. (1995). L-NOARG, an inhibitor of nitric oxide synthase, 
induces catalepsy in mice. Neuroreport, 7, 158-160.

Millan, M. J., Maiofiss, L., Cussac, D., Audinot, V., Boutin, J. A., \& Newman-Tancredi, A. (2002). Differential actions of antiparkinson agents at multiple classes of monoaminergic receptor. I. A multivariate analysis of the binding profiles of 14 drugs at 21 native and cloned human receptor subtypes. The Journal of Pharmacology \& Experimental Therapeutics, 303, 791-804.

Missale, C., Nash, S. R., Robinson, S. W., Jaber, M., \& Caron, M. G. (1998). Dopamine receptors: From structure to function. Physiological Reviews, 78, 189-225.

Moore, H., West, A. R., \& Grace, A. A. (1999). The regulation of forebrain dopamine transmission: Relevance to the pathophysiology and psychopathology of schizophrenia. Biological Psychiatry, 46, 40-55.

Morris, B. J., Simpson, C. S., Mundell, S., Maceachern, K., Johnston, H. M., \& Nolan, A. M. (1997). Dynamic changes in NADPH-diaphorase staining reflect activity of nitric oxide synthase: Evidence for a dopaminergic regulation of striatal nitric oxide release. Neuropharmacology, 36, 1589-1599.

Noda, Y., Yamada, K., Furukawa, H., \& Nabeshima, T. (1995). Involvement of nitric oxide in phencyclidine-induced hyperlocomotion in mice. European Journal of Pharmacology, 286, 291-297.

O'Tuathaigh, C. M., Salum, C., Young, A. M., Pickering, A. D., Joseph, M. H., \& Moran, P. M. (2003). The effect of amphetamine on Kamin blocking and overshadowing. Behavioural Pharmacology, 14, 315-322.

Paladini, C. A., Robinson, S., Morikawa, H., Williams, J. T., \& Palmiter, R. D. (2003). Dopamine controls the firing pattern of dopamine neurons via a network feedback mechanism. Proceedings of the National Academy of Sciences of the United States of America, 100, 2866-2871.

Ramirez, J., Garnica, R., Boll, M. C., Montes, S., \& Rios, C. (2004). Low concentration of nitrite and nitrate in the cerebrospinal fluid from schizophrenic patients: A pilot study. Schizophrenia Research, 68, 357-361.

Rocchitta, G., Migheli, R., Mura, M. P., Grella, G., Esposito, G., Marchetti, B., Miele, E., Desole, M. S., Miele, M., \& Serra, P. A. (2005). Signaling pathways in the nitric oxide and ironinduced dopamine release in the striatum of freely moving rats: Role of extracellular Ca2+ and L-type $\mathrm{Ca} 2+$ channels. Brain Research, 1047, 18-29.

Salum, C., Guimaraes, F. S., Brandao, M. L., \& Del Bel, E. A. (2006). Dopamine and nitric oxide interaction on the modulation of prepulse inhibition of the acoustic startle response in the Wistar rat. Psychopharmacology (Berl), 185, 133-141.

Seeman, P., \& Kapur, S. (2000). Schizophrenia: More dopamine, more D2 receptors. Proceedings of the National Academy of Sciences of the United States of America, 97, 7673-7675.

Snyder, S. H. \& Bredt, D. S. (1991). Nitric-oxide as a neuronal messenger. Trends in Pharmachological Science, 12, 125-128.

Snyder, S. H. \& Ferris, C. D. (2000). Novel neurotransmitters and their neuropsychiatric relevance. American Journal of Psychiatry, 11, 1738-1751.

Sulzer, D., Maidment, N. T., \& Rayport, S. (1993). Amphetamine and other weak bases act to promote reverse transport of dopamine in ventral midbrain neurons. Journal of Neurochemistry, 60, 527-535.

Swerdlow, N. R., Caine, S. B., Braff, D. L., \& Geyer, M. A. (1992). Neural substrates of sensorimotor gating of the startle reflex: A review of recent findings and their implications. Journal of Psychopharmacology, 6, 176-190.
Swerdlow, N. R., Shoemaker, J. M., Auerbach, P. P., Pitcher, L., Goins, J., \& Platten, A. (2004). Heritable differences in the dopaminergic regulation of sensorimotor gating. II. Temporal, pharmacologic and generational analyses of apomorphine effects on prepulse inhibition. Psychopharmacology (Berl), 174, 452-462.

Swerdlow, N. R., Stephany, N., Wasserman, L. C., Talledo, J., Shoemaker, J. M., \& Auerbach, P. P. (2003). Amphetamine effects on prepulse inhibition across-species replication and parametric extension. Neuropsychopharmachology, 28, 640650.

Van Horn, J. D., \& McManus, I. C. (1992). Ventricular enlargement in schizophrenia. A meta-analysis of studies of the Ventricle Brain Ratio (VBR). The British Journal of Psychiatry, 160, 687-697.

Varty, G. B., \& Higgins, G. A. (1998). Dopamine agonist-induced hypothermia and disruption of prepulse inhibition: Evidence for a role of D3 receptors? Behavioural Pharmacology, 9, 445455.

Wan, F. J., Geyer, M. A., \& Swerdlow, N. R. (1995). Presynaptic dopamine-glutamate interactions in the nucleus accumbens regulate sensorimotor gating. Psychopharmacology, 120, 433441.

Weiss, S. M., \& Feldon, J. (2001). Environmental animal models for sensorimotor gating deficiencies in schizophrenia: A review. Psychopharmacology, 156, 305-326.

West, A. R., \& Galloway, M. P. (1997). Endogenous nitric oxide facilitates striatle dopamine and glutamate efflux in vivo: Role of ionotropic glutamate receptor-dependent mechanisms. Neuropharmacology, 279, 1571-1581.

West, A. R., Galloway, M. P., \& Grace, A. A. (2002). Regulation of striatal dopamine neurotransmission by nitric oxide: Effector pathways and signaling mechanisms. Synapse, 44, 227-245.

Wong, A. H., \& Van Tol, H. H. (2003). Schizophrenia: From phenomenology to neurobiology. Neuroscience and Biobehavioral Reviews, 27, 269-306.

Wright, I. C., Rabe-Hesketh, S., Woodruff, P. W., David, A. S., Murray, R. M., \& Bullmore, E. T. (2000). Meta-analysis of regional brain volumes in schizophrenia. American Journal of Psychiatry, 157, 16-25.

Yamada, S., Harano, M., \& Tanaka, M. (1998). Dopamine autoreceptors in rat nucleus accumbens modulate prepulse inhibition of acoustic startle. Pharmacology, Biochemistry, and Behavior, 60, 803-808.

Zhang, J., Forkstam, C., Engel, J. A., \& Svensson, L. (2000). Role of dopamine in prepulse inhibition of acoustic startle. Psychopharmacology, 149, 181-188.

Zhang, J., \& Snyder, S. H. (1995). Nitric oxide in the nervous system. Annual Review of Pharmacology and Toxicology, 35, 213-233. 